Article

\title{
Experimental Study on the Inhibition Effects of Nitrogen and Carbon Dioxide on Coal Spontaneous Combustion
}

\author{
Yi Zhang ${ }^{1,2,3, *}$, Jun $\mathrm{Xu}^{1,2}$ and Deming Wang ${ }^{1,2}$ \\ 1 School of Safety Engineering, China University of Mining and Technology, Xuzhou 221116, China; \\ TS20120045A31@cumt.edu.cn (J.X.); dmwang@cumt.edu.cn (D.W.) \\ 2 Key Laboratory of Gas and Fire Control for Coal Mines (China University of Mining and Technology), \\ Ministry of Education, Xuzhou 221116, China \\ 3 Xuzhou Anyun Mining Technology Inc., Xuzhou 221008, China \\ * Correspondence: LB16120026@cumt.edu.cn; Tel.: +86-158-5235-6577
}

Received: 3 September 2020; Accepted: 3 October 2020; Published: 10 October 2020

\begin{abstract}
Inert gases can effectively inhibit coal spontaneous combustion. In this paper, the inhibition effect of inert gases $\left(\mathrm{N}_{2}\right.$ and $\left.\mathrm{CO}_{2}\right)$ on coal spontaneous combustion was studied. In the low-temperature oxidation stage, the constant-temperature heat release and apparent activation energy of coal sample were measured and calculated by the C80 micro-calorimeter. In the high-temperature combustion stage, the critical temperature, maximum peak temperature, ignition temperature, and burn-out temperature of coal samples were analyzed by the synchronous thermal analyzer. The results demonstrate that with the decrease of $\mathrm{O}_{2}$ concentration, the oxidation heat release of coal samples drops gradually while the apparent activation energy increases gradually. In the $\mathrm{N}_{2}$ and $\mathrm{CO}_{2}$ atmospheres, as the $\mathrm{O}_{2}$ concentration is reduced to $1.5 \%$ and $3 \%$, respectively, the value of apparent activation energy changes from negative to positive, and the spontaneous reaction transits to a nonspontaneous reaction. The TG-DTG (thermogravimetric-derivative thermogravimetric) curve of coal sample in the high-temperature combustion stage indicates that the critical temperature exhibits a W-shaped trend with the decrease of $\mathrm{O}_{2}$ concentration, which also leads to gradual increases of maximum peak temperature, ignition temperature, and burn-out temperature. The above results signify that increasing the inert gas concentration can gradually reduce the oxidation and combustion rate and improve the inhibition effect on coal spontaneous combustion. In addition, when the $\mathrm{O}_{2}$ concentration is the same, the inhibition effect of $\mathrm{CO}_{2}$ on coal spontaneous combustion is superior to that of $\mathrm{N}_{2}$.
\end{abstract}

Keywords: coal spontaneous combustion; inhibition effect; nitrogen; carbon dioxide

\section{Introduction}

Coal is an important energy source and chemical raw materials [1-4]. Many disasters may occur in the process of coal mining [5-11]. As one of the main disasters, coal spontaneous combustion (CSC) not only burns vast coal resources and releases toxic gases but also causes casualties [12-14]. In China, $56 \%$ of state-owned coal mines have suffered from CSC, accounting for $90-94 \%$ of all mine fires [15]. Because coal is a complex organic substance, it will adsorb $\mathrm{O}_{2}$ to undergo a chain reaction and then release heat when exposed to an $\mathrm{O}_{2}$ environment. If the accumulated heat cannot be dissipated, CSC is likely to occur [16]. Therefore, it is of great significance to study the prevention and control technology of coal spontaneous fire to ensure the safety of mine production.

Currently, scholars have carried out extensive researches on prevention and extinguishing materials for CSC, such as gel foam [17], ionic liquid [14], inorganic solidified foam [18], and gel [19], which all 
exert satisfactory effects on coal spontaneous fire prevention and control. However, coal spontaneous fires mostly occur in underground concealed spaces. According to statistics, $60 \%$ of CSC occurs in the goaf area $[15,20]$. Due to large space in the goaf area and wide distribution of residual coal, the dangerous areas of CSC present a three-dimensional distribution. Thus, it is difficult to determine the exact location of fire area, which poses a considerable challenge to fire prevention and extinguishing technology of CSC. Inert gases have been gradually applied to CSC prevention and control in the goaf area because of their excellent diffusivity [21-23]. However, many problems still arise in the field application of fire prevention and extinguishing technology of inert gases. For example, inert gas perfusion fails to achieve a satisfactory fire prevention and extinguishing effect; index gases like $\mathrm{CO}$ are difficult to be reduced and maintained to below the safety level; the sealed working face is prone to reburn after it is reopened [24]. Hence, an indepth research on the fire prevention and extinguishing performance of gaseous inert media is essential.

$\mathrm{O}_{2}$ concentration is an important factor affecting the characteristics of CSC [25]. In fact, the technology of fire prevention and extinguishing by inert gases mainly achieves the purpose of inhibiting coal oxidation and spontaneous combustion by lowering the $\mathrm{O}_{2}$ concentration in the environment. In recent years, some scholars have investigated the effect of $\mathrm{O}_{2}$ concentration on the characteristics of coal oxidation and spontaneous combustion under inert gas conditions. Lei et al. [26] studied the inhibition effects of inert gases $\left(\mathrm{N}_{2}\right.$ and $\left.\mathrm{CO}_{2}\right)$ on open flame coal combustion, with the $\mathrm{O}_{2}$ concentration ranging from $16.39 \%$ to $19.01 \%$. The results revealed that $\mathrm{N}_{2}$ reduced the flame area linearly while $\mathrm{CO}_{2}$ reduced the flame area exponentially. In addition, $\mathrm{CO}_{2}$ extinguished fire faster than $\mathrm{N}_{2}$. Shao et al. [27] carried out the contrast experiment of temperature-programmed oxidation of coal samples under the conditions of air, $\mathrm{N}_{2}$-air mixture and $\mathrm{CO}_{2}$-air mixture. In the experiment, the $\mathrm{O}_{2}$ concentration ranged from $17.07 \%$ to $17.55 \%$, and the temperature ranged from $20^{\circ} \mathrm{C}$ to $110{ }^{\circ} \mathrm{C}$. The inhibition effects of $\mathrm{N}_{2}$ and $\mathrm{CO}_{2}$ on CSC were analyzed by apparent activation energy. Liu et al. [28] studied the thermokinetic characteristics of coal- $\mathrm{O}_{2}$ reaction with the $\mathrm{O}_{2}$ concentration ranging from $3 \%$ to $21 \%$ in $\mathrm{N}_{2}-\mathrm{O}_{2}$ and $\mathrm{CO}_{2}$-air atmospheres through TG-DTG-DSC (thermogravimetric-derivative thermogravimetric-differential scanning calorimetry) experiments. The results showed that the coal- $\mathrm{O}_{2}$ reaction rate could be reduced rapidly by injecting $\mathrm{N}_{2}$ and $\mathrm{CO}_{2}$. Among them, the $\mathrm{CO}_{2}$-air mixture was actually an $\mathrm{O}_{2}-\mathrm{N}_{2}-\mathrm{CO}_{2}$ mixture, rather than a $\mathrm{CO}_{2}-\mathrm{O}_{2}$ mixture. Consequently, the inhibition effects of $\mathrm{N}_{2}$ and $\mathrm{CO}_{2}$ could hardly be truly compared. Deng et al. [29] investigated the characteristic parameters of coal oxidation in the $\mathrm{O}_{2}-\mathrm{N}_{2}$ atmosphere and the $\mathrm{O}_{2}-\mathrm{CO}_{2}$ atmosphere at low temperatures $\left(30-170{ }^{\circ} \mathrm{C}\right)$ under the $\mathrm{O}_{2}$ concentrations of $4 \%, 8 \%, 14 \%$, and $21 \%$, concluding that the $\mathrm{O}_{2}$ consumption rate in the $\mathrm{O}_{2}-\mathrm{CO}_{2}$ atmosphere was lower than that in the $\mathrm{O}_{2}-\mathrm{N}_{2}$ atmosphere when the $\mathrm{O}_{2}$ concentration was the same.

The oxygen concentration settings in experiments done by other researchers are listed below. $\mathrm{Li}$ et al. [30] researched the macro-characteristic indexes of coal samples at different $\mathrm{O}_{2}$ concentrations $(3 \%, 8 \%, 13 \%, 17 \%$, and $21 \%)$ with the temperature ranging from $30{ }^{\circ} \mathrm{C}$ to $500{ }^{\circ} \mathrm{C}$. Ma et al. [31] probed into the thermokinetic characteristics of coal samples when they were heated from $30^{\circ} \mathrm{C}$ to $800{ }^{\circ} \mathrm{C}$ under the $\mathrm{N}_{2}$ atmosphere with $\mathrm{O}_{2}$ concentrations being $5 \%, 9 \%, 13 \%, 17 \%$, and $21 \%$, respectively. Ren et al. [32] explored the thermodynamic behavior of coal sample oxidation with $\mathrm{O}_{2}$ concentrations being $8 \%, 14 \%$, and $21 \%$ under the $\mathrm{O}_{2}-\mathrm{N}_{2}-\mathrm{CO}_{2}$ atmosphere and the $\mathrm{O}_{2}-\mathrm{N}_{2}$ atmosphere, respectively. Zhang et al. [33] studied the thermogravimetric characteristics of coal oxidation and spontaneous combustion under the $\mathrm{N}_{2}$ atmosphere with $\mathrm{O}_{2}$ concentrations being $5 \%, 12.5 \%$, and $21 \%$, respectively.

To sum up, most of the current experimental studies focus on an $\mathrm{O}_{2}$ concentration of over $5 \%$, and there is a lack of understanding of the characteristics of inert gas inhibiting coal oxidation and spontaneous combustion under poor $\mathrm{O}_{2}$ conditions. Furthermore, in the laboratory, only oxidation heating experiments in the fire prevention stage (from the room temperature to the target temperature) are performed, whereas the inerting and inhibition effects of inert gases on high-temperature combusting coal in the fire extinguishing stage are rarely researched on. Therefore, it is necessary to study the fire prevention performance at low temperatures and the fire extinguishing performance at high 
temperatures of inert gases under poor $\mathrm{O}_{2}$ conditions. In this paper, the inhibition effects of inert gases $\left(\mathrm{N}_{2}\right.$ and $\left.\mathrm{CO}_{2}\right)$ in the low-temperature oxidation stage and the high-temperature combustion stage of CSC under different $\mathrm{O}_{2}$ concentration conditions were studied with the aid of the micro-calorimeter and the synchronous thermal analyzer. The research was conducted from the perspectives of heat release, activation energy, critical temperature, maximum peak temperature, ignition temperature, and burn-out temperature. The research findings can provide a theoretical guidance for the practical application of technology of fire prevention and extinguishing by inert gases.

\section{Experimental Procedure}

\subsection{Materials}

The coal samples used in the experiment were collected from Luxin No.1 Mine and transported to the laboratory after being wrapped with plastic wrap and putting in plastic sealed bags. The lump coal samples were crushed and those with particle sizes of 100-200 meshes and 200-300 meshes were screened out for subsequent experiments. The proximate analysis results of coal samples are shown in Table 1. The purity of $\mathrm{O}_{2}, \mathrm{~N}_{2}$, and $\mathrm{CO}_{2}$ is $99.99 \%$.

Table 1. Proximate analysis results of coal sample.

\begin{tabular}{ccccc}
\hline \multirow{2}{*}{ Coal Sample } & Mad/(wt $\%)$ & Aad/(wt $\%)$ & Vad/(wt $\%)$ & FCad/(wt $\%)$ \\
\cline { 2 - 5 } & 12.445 & 6.18 & 29.01 & 52.365 \\
\hline
\end{tabular}

\subsection{C80 Micro-Calorimeter}

The oxidation heat release properties of coal samples in the $\mathrm{N}_{2}$ and $\mathrm{CO}_{2}$ atmospheres under different $\mathrm{O}_{2}$ concentrations were analyzed by the $\mathrm{C} 80$ micro-calorimeter produced by Setaram, France (Figure 1). In the experiment, the amount of coal sample was $1000 \mathrm{mg}$; the gas flow rate was $50 \mathrm{~mL} / \mathrm{min}$; and the $\mathrm{O}_{2}$ concentration was set at $21 \%, 10 \%, 5 \%, 3 \%$, and $1.5 \%$, respectively. The coal sample was heated from the initial temperature of $20^{\circ} \mathrm{C}$ to the constant temperatures $140{ }^{\circ} \mathrm{C}, 145^{\circ} \mathrm{C}$, and $150{ }^{\circ} \mathrm{C}$, respectively, at a heating rate of $5^{\circ} \mathrm{C} / \mathrm{min}$. First, the inert gas was injected. After the heat flow curve was balanced and run for $120 \mathrm{~min}, \mathrm{O}_{2}$ was introduced through the $\mathrm{O}_{2}$ pipeline flowmeter. During the experiment, the furnace temperature, coal temperature, and heat flow parameters of the coal sample were recorded. 


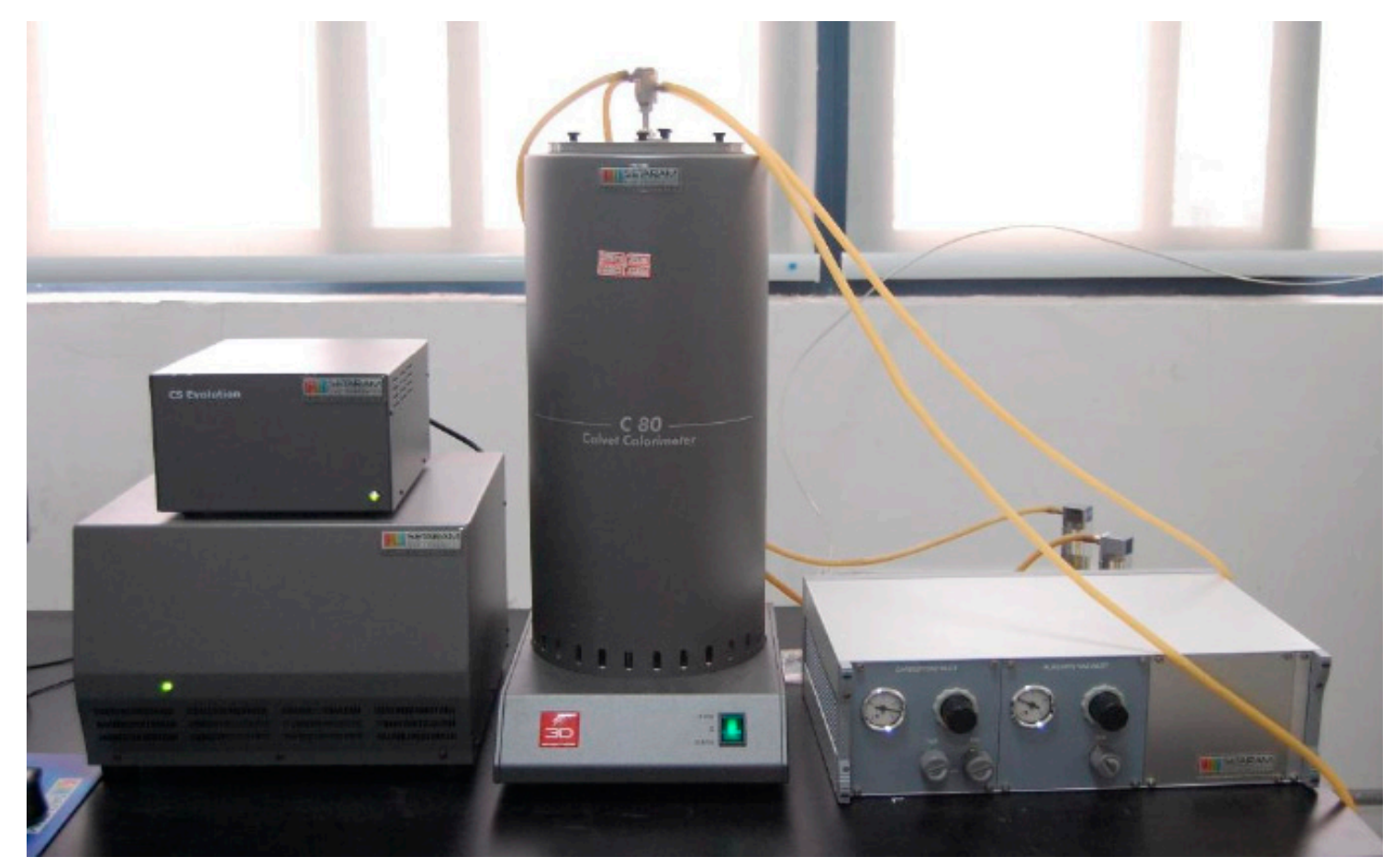

Figure 1. C80 micro-calorimeter.

\subsection{Synchronous Thermal Analyzer}

The inhibition effects of inert gases in the high-temperature combustion stage were studied with the aid of the SDT-Q600 synchronous thermal analyzer produced by TA Company, the USA (Figure 2). In the experiment, the mass of coal sample was $5 \mathrm{mg}$ and the particle size of coal sample was $\mathrm{m}$. The furnace temperature was raised from $20^{\circ} \mathrm{C}$ to $1000^{\circ} \mathrm{C}$ at a heating rate of $5^{\circ} \mathrm{C}$ min, with the gas flow rate set at $50 \mathrm{~mL} / \mathrm{min}$, and the $\mathrm{O}_{2}$ concentration set at $21 \%, 15 \%, 10 \%, 5 \%, 3 \%$, and $1.5 \%$, respectively.

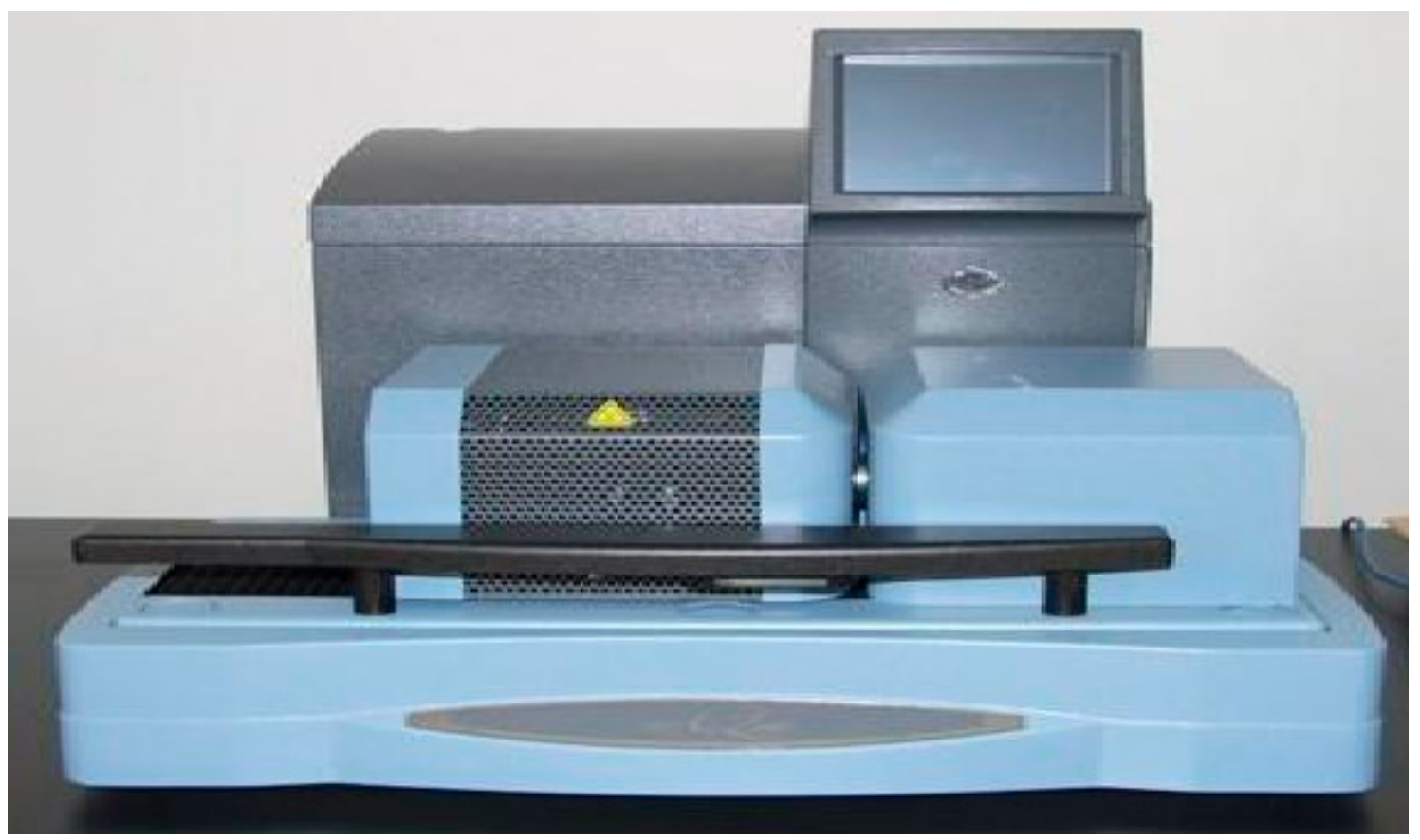

Figure 2. SDT-Q600 synchronous thermal analyzer. 


\section{Results and Discussion}

\subsection{Inhibition Effects of Inert Gases in the Low-temperature Oxidation Stage}

\subsubsection{Constant-Temperature Heat Release}

The heat flow curves of coal samples with different $\mathrm{O}_{2}$ concentrations in the $\mathrm{N}_{2}$ and $\mathrm{CO}_{2}$ atmospheres were obtained by the C80 micro-calorimeter, and the overall heat release of coal samples from the heat release stage to the constant temperature stage (a total of $15 \mathrm{~h}$ ) was acquired by integration, as shown in Figure 3.

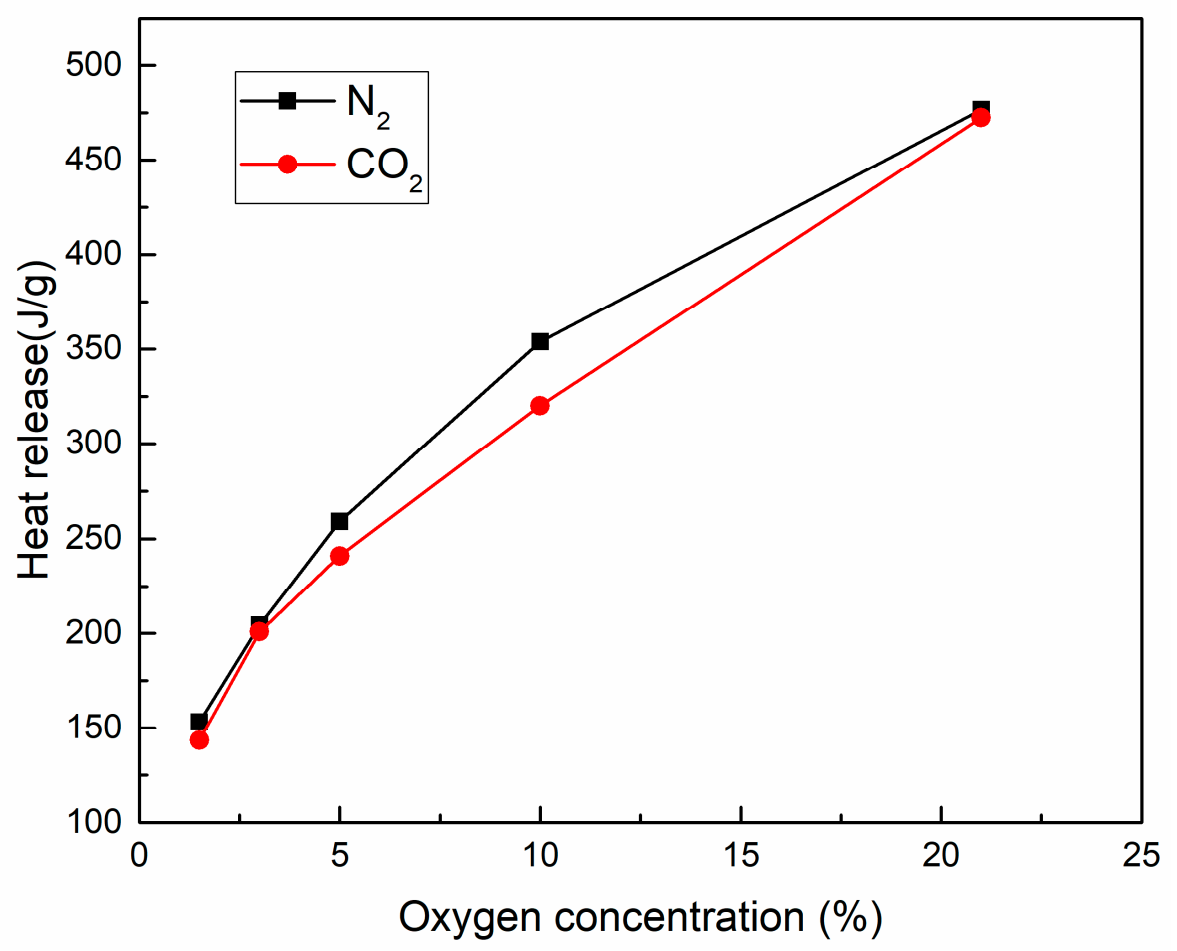

Figure 3. Heat release of coal oxidation in the $\mathrm{N}_{2}$ and $\mathrm{CO}_{2}$ atmospheres.

Low-temperature oxidation of coal usually includes two stages: the water evaporation stage and the $\mathrm{O}_{2}$ adsorption and weight increase stage. The constant temperatures $\left(140{ }^{\circ} \mathrm{C}, 145{ }^{\circ} \mathrm{C}\right.$, and $\left.150{ }^{\circ} \mathrm{C}\right)$ selected in the experiment belong to the second stage. The $\mathrm{O}_{2}$ adsorption reaction is an exothermic reaction that causes an increase in the weight of the system. The released heat of coal directly depends on its $\mathrm{O}_{2}$ adsorption and also indicates the difficulty in coal oxidation reaction. To be specific, the smaller the heat release is, the better the inhibition effect of inert gas in the low-temperature oxidation stage will be. It can be seen from Figure 3 that with the decrease of $\mathrm{O}_{2}$ concentration, i.e., the increase of inert gas concentration, the heat release of coal gradually decreases at an accelerated rate. This denotes that the $\mathrm{O}_{2}$ concentration in the fire area should be minimized in order to improve the inhibition effect of inert gas on low-temperature oxidation of coal. In addition, the coal sample in the $\mathrm{CO}_{2}$ atmosphere always releases less heat than the one in the $\mathrm{N}_{2}$ atmosphere at the same $\mathrm{O}_{2}$ concentration, which implies that $\mathrm{CO}_{2}$ shows a better inhibition effect in the low-temperature oxidation stage than $\mathrm{N}_{2}$.

\subsubsection{Apparent Activation Energy}

Activation energy refers to the minimum energy required for the oxidation reaction to proceed. The greater the activation energy, the more difficult the reaction is. For the coal- $\mathrm{O}_{2}$ reaction, the low-temperature oxidation involves a variety of elementary reactions, and its activation energy usually refers to the apparent activation energy. In this paper, the heat release properties of coal 
oxidation under three isotherms $\left(140^{\circ} \mathrm{C}, 145^{\circ} \mathrm{C}\right.$, and $\left.150^{\circ} \mathrm{C}\right)$ are used to calculate the law of activation energy variation with the $\mathrm{O}_{2}$ concentration.

The time when $\mathrm{O}_{2}$ is injected into the system at different temperatures is defined as the initial exothermic time. Until the temperature is kept at a constant temperature for $15 \mathrm{~h}$, the whole exothermic process is regarded as a complete reaction. That is, the reaction process is 1 . According to the Arrhenius Equation:

$$
\ln k=-\frac{E}{R T}+\ln A
$$

where $A$ is the pre-exponential factor; $E$ is the activation energy; $T$ is the temperature of coal sample; $R$ is the universal gas constant, $8.314 \mathrm{~J} / \mathrm{mol} \cdot \mathrm{K}$; and $k$ is the reaction rate constant.

With $\ln k$ and 1000/T as straight lines, the activation energy $E$ and the pre-exponential factor $A$ are calculated according to the slope and intercept. The calculation results are exhibited in Figure 4.

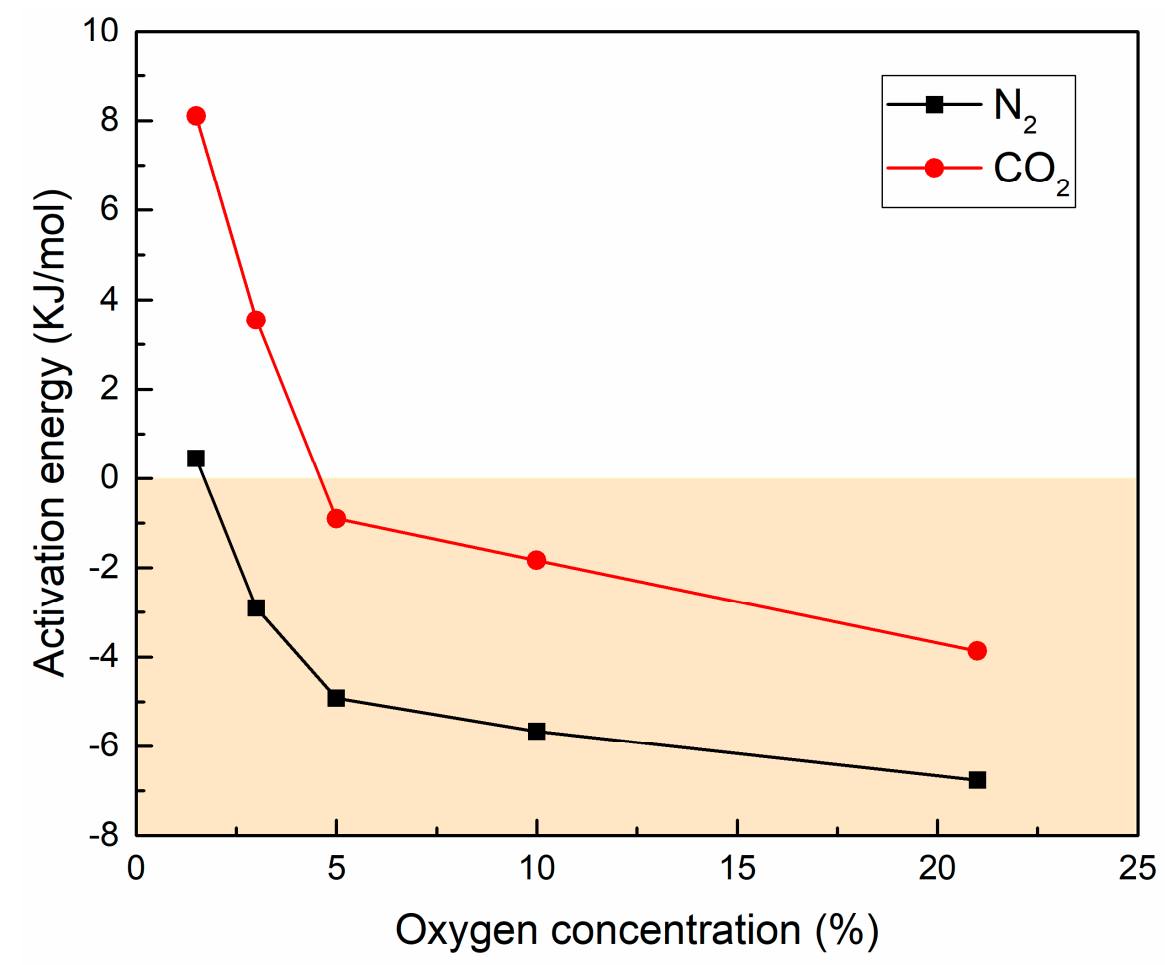

Figure 4. Activation energy of coal oxidation in the $\mathrm{N}_{2}$ and $\mathrm{CO}_{2}$ atmospheres.

It can be seen from Figure 4 that the activation energy of coal oxidation reaction increases gradually with the decrease of $\mathrm{O}_{2}$ concentration, because $\mathrm{N}_{2}$ and $\mathrm{CO}_{2}$, as inert gases, do not react with coal. With the decrease of $\mathrm{O}_{2}$ concentration, $\mathrm{O}_{2}$ that can participate in the coal oxidation reaction gradually decreases. As a result, the coal oxidation reaction is inhibited, which promotes the reaction difficulty, so the apparent activation energy increases. As the $\mathrm{O}_{2}$ concentration decreases, the value of activation energy transits from negative to positive. A negative value of activation energy indicates that there is no reaction barrier, and the reaction can proceed spontaneously. In contrast, a positive value of activation energy suggests that there is a reaction barrier, and the reaction cannot proceed spontaneously. In the $\mathrm{N}_{2}$ atmosphere, the value of activation energy is positive when the $\mathrm{O}_{2}$ concentration declines to $1.5 \%$, while in the $\mathrm{CO}_{2}$ atmosphere, the value of activation energy is positive only when the $\mathrm{O}_{2}$ concentration drops to below $3 \%$. For the $\mathrm{N}_{2}$ and $\mathrm{CO}_{2}$ atmospheres, the activation energy was negative when the $\mathrm{O}_{2}$ concentration is greater than $1.5 \%$ and $3 \%$, respectively, indicating that the inert gases cannot prevent the spontaneous process of the coal-oxygen reaction. The above phenomena demonstrate that under the $\mathrm{N}_{2}$ and $\mathrm{CO}_{2}$ conditions, only when the $\mathrm{O}_{2}$ concentration is reduced to $1.5 \%$ and $3 \%$, respectively, can inert gas significantly inhibit the low-temperature oxidation of coal. 
Furthermore, it can be observed from Figure 4 that under the same $\mathrm{O}_{2}$ concentration, the activation energy of coal oxidation reaction in the $\mathrm{CO}_{2}$ atmosphere is higher than that in the $\mathrm{N}_{2}$ atmosphere, which implies that $\mathrm{CO}_{2}$ exhibits a better inhibition effect on the low-temperature oxidation than $\mathrm{N}_{2}$. The reason is as follows: during the coal oxidation reaction, coal will simultaneously adsorb $\mathrm{O}_{2}$ and inert gases. If coal exhibits stronger adsorption capacity for inert gases, then its adsorption capacity for $\mathrm{O}_{2}$ will be weaker. In the inert gas atmosphere with the same $\mathrm{O}_{2}$ concentration, the adsorption capacity of coal to $\mathrm{CO}_{2}$ is stronger than that to $\mathrm{N}_{2}$, so the $\mathrm{O}_{2}$ absorption capacity of coal in the $\mathrm{CO}_{2}$ atmosphere is weaker than that in the $\mathrm{N}_{2}$ atmosphere. Therefore, the coal oxidation reaction is inhibited to a greater extent in the $\mathrm{CO}_{2}$ atmosphere, and the activation energy is greater than that in the $\mathrm{N}_{2}$ atmosphere.

\subsection{Inhibition Effects of Inert Gases in the High-Temperature Combustion Stage}

This section primarily presents an analysis on the inhibition effects of inert gases on high-temperature combustion of coal. Thermo-gravimetry is used to investigate the variation characteristics of characteristic temperatures (including critical temperature, maximum peak temperature, ignition temperature, and burn-out temperature) in the oxidation combustion reaction of coal samples in the inert gas atmospheres at different $\mathrm{O}_{2}$ concentrations.

\subsubsection{Critical Temperature}

In the CSC process, there is a turning point from low-temperature slow oxidation to rapid oxidation. When the temperature exceeds the turning point, the coal- $\mathrm{O}_{2}$ reaction rate accelerates and enters the rapid oxidation stage. The temperature at this turning point is called the critical temperature, namely the temperature corresponding to the first peak on the DTG curve of coal sample [34] (Figure 5).

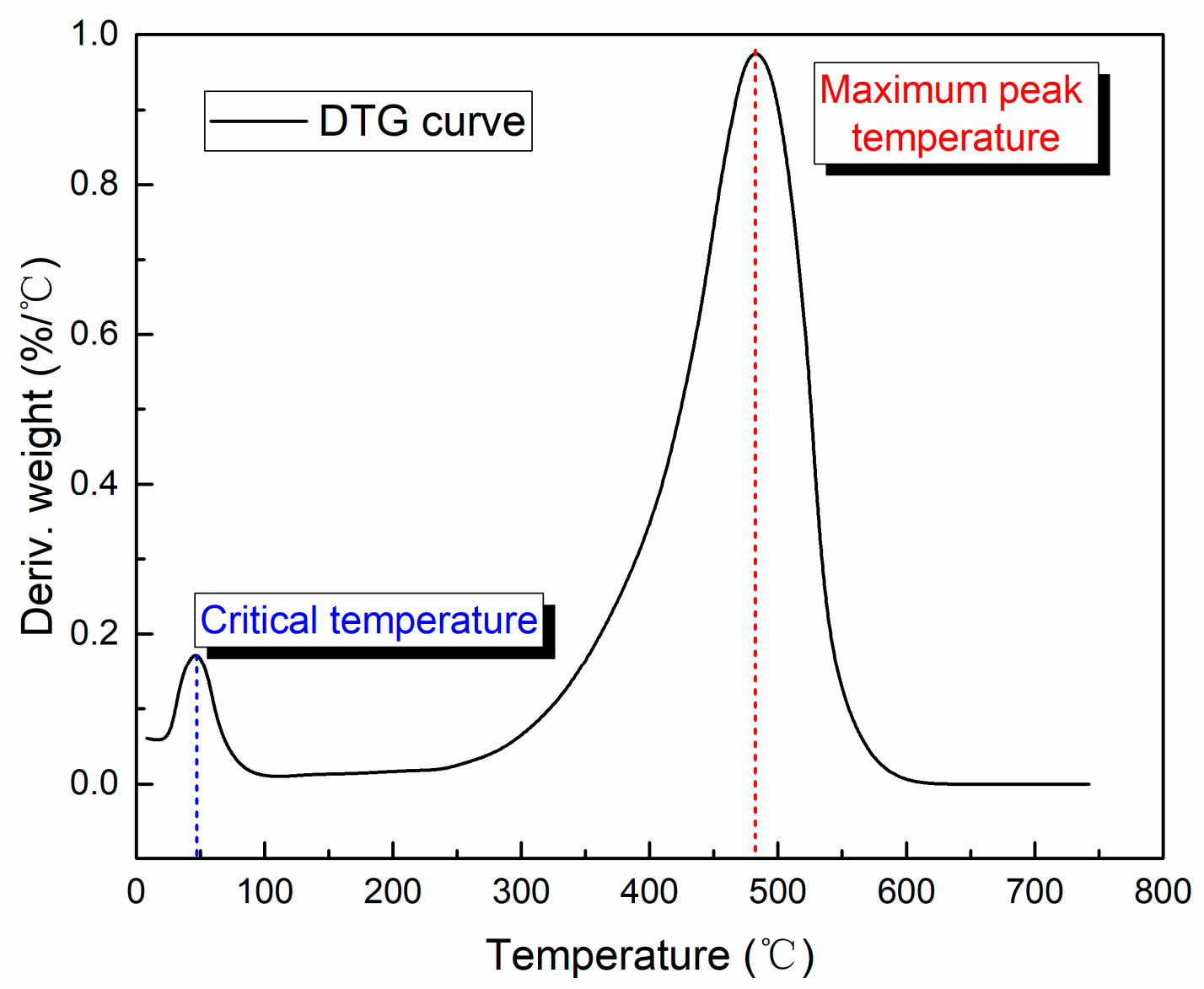

Figure 5. Definitions of critical temperature and maximum peak temperature. 
The critical temperature of coal sample implies the starting point of automatic acceleration of coal- $\mathrm{O}_{2}$ reaction, and its value reflects the spontaneous combustion tendency of coal sample. A larger value of critical temperature indicates that coal oxidation combustion is less likely to occur. On the contrary, a small value of critical temperature suggests that the possibility of coal oxidation combustion is very high. According to the DTG curve, the obtained critical temperature values of coal samples with different $\mathrm{O}_{2}$ concentrations in the $\mathrm{N}_{2}$ and $\mathrm{CO}_{2}$ atmospheres are displayed in Figure 6.

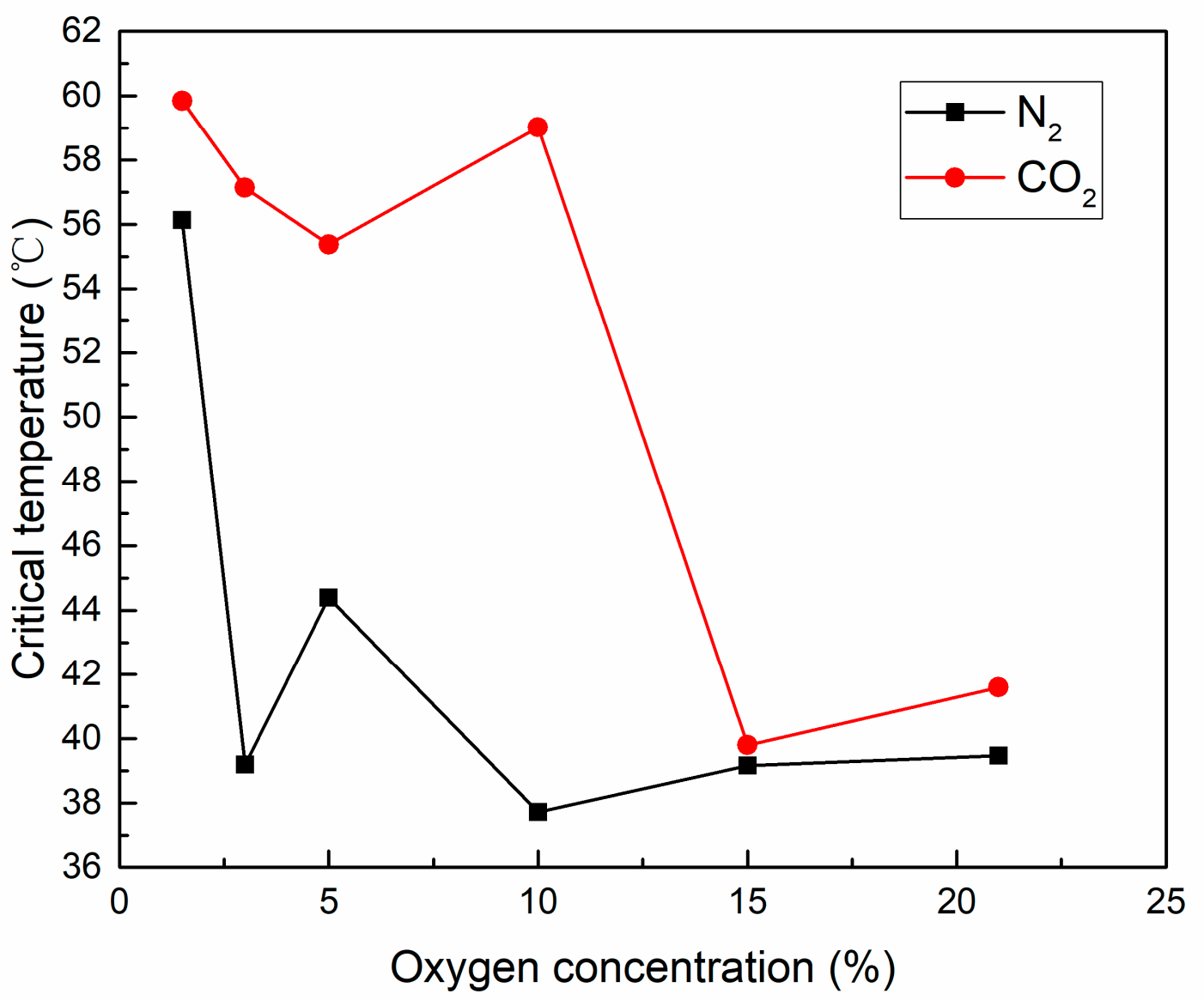

Figure 6. Critical temperatures of coal sample in the $\mathrm{N}_{2}$ and $\mathrm{CO}_{2}$ atmospheres.

Figure 6 reveals that in the $\mathrm{N}_{2}$ and $\mathrm{CO}_{2}$ atmospheres, the critical temperature of the coal sample presents a $\mathrm{W}$-shaped trend with the decrease of $\mathrm{O}_{2}$ concentration. Specifically, the critical temperature declines at first and increases later, and then repeats that trend again, but its overall trend is to increase with the decrease of $\mathrm{O}_{2}$ concentration. The reason is as follows: at a low $\mathrm{O}_{2}$ concentration, the rate of physical and chemical interaction between the coal sample and $\mathrm{O}_{2}$ is low, and the time for reaching a dynamic equilibrium between the weight increase brought by $\mathrm{O}_{2}$ adsorption and the weight reduction induced by reaction consumption and gas escape lengthens. This signifies that the time required to reach the critical temperature is prolonged, resulting in a higher critical temperature. With the increase of $\mathrm{O}_{2}$ concentration, the probability of contact between active groups in coal and $\mathrm{O}_{2}$ increases, which accelerates the coal- $\mathrm{O}_{2}$ reaction. The amount of $\mathrm{O}_{2}$ adsorbed by the coal sample is balanced with the amount of gas consumed and desorbed in a short period of time. Thus, the value of temperature rise is relatively reduced, which presents a lower critical temperature. With the increases of oxygen consumption and gas desorption volume, the $\mathrm{O}_{2}$ adsorption and reaction rate of coal sample are hindered, leading to a higher critical temperature. As the $\mathrm{O}_{2}$ concentration continues to go up, the $\mathrm{O}_{2}$ concentration gradient formed in the direction of the coal seam thickness increases, so do the $\mathrm{O}_{2}$ diffusion rate and the coal- $\mathrm{O}_{2}$ reaction rate, thus the critical temperature falls. When the $\mathrm{O}_{2}$ concentration continues to rise, the gas concentration gradient will once again hinder the desorption 
and escape of gas products inside the coal sample, thereby inhibiting the coal- $\mathrm{O}_{2}$ reaction, and causing the critical temperature to rise again.

\subsubsection{Maximum Peak Temperature}

The maximum peak temperature of coal sample refers to the temperature corresponding to the highest peak in the DTG curve (Figure 5). When the coal sample reaches the maximum peak temperature, the weight loss rate hits its largest, indicating that the coal sample comes to the highest combustion rate. On the basis of the DTG curve, the maximum peak temperatures of coal samples with different $\mathrm{O}_{2}$ concentrations under inert gas conditions are shown in Figure 7.

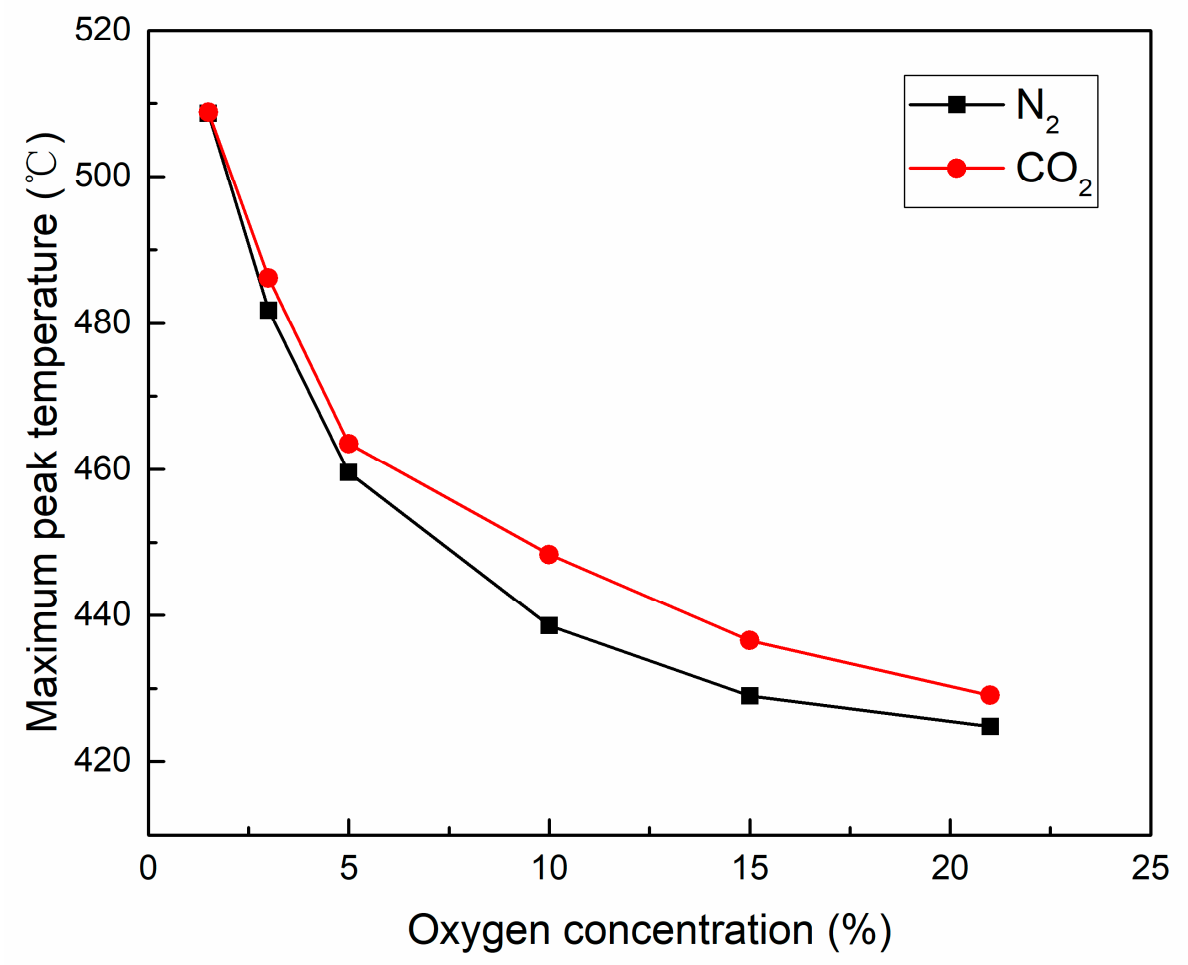

Figure 7. Maximum peak temperature of coal sample in the $\mathrm{N}_{2}$ and $\mathrm{CO}_{2}$ atmospheres.

It can be seen from Figure 7 that the maximum peak temperatures of coal samples increase gradually with the decrease of $\mathrm{O}_{2}$ concentration in the inert gas atmospheres. The reason is as follows: the decrease of $\mathrm{O}_{2}$ concentration signifies the increase of inert gas concentration, which not only considerably inhibits the formation of active functional groups in the coal structure but also notably suppresses the oxidative cracking of macro-molecular cyclic hydrocarbon structure. Hence, the time required for the coal oxidation and combustion rate to reach the maximum value is prolonged, resulting in a rise of the maximum peak temperature. Figure 7 demonstrates that with the decrease of $\mathrm{O}_{2}$ concentration, the rate of peak temperature increase is growing. This suggests that increasing the inert gas concentration can delay high-temperature combustion. In addition, a lower $\mathrm{O}_{2}$ concentration exerts an obvious impact on the peak temperature, namely a better inhibition effect on coal combustion. Moreover, under the same $\mathrm{O}_{2}$ concentration, the maximum peak temperature in the $\mathrm{CO}_{2}$ atmosphere is always higher than that in the $\mathrm{N}_{2}$ atmosphere, which implies that $\mathrm{CO}_{2}$ shows a better inhibition effect in the high-temperature combustion stage than $\mathrm{N}_{2}$.

\subsubsection{Ignition Temperature and Burn-Out Temperature}

The ignition temperature of coal sample, which is the dividing point between coal oxidation reaction and combustion reaction, reflects the difficulty in coal oxidation and combustion. The burn-out 
temperature of coal sample, which corresponds to the temperature where the weight of coal sample no longer changes in the combustion stage, represents the duration of coal oxidation and combustion. The ignition temperature and burn-out temperature of coal sample vary with the change of $\mathrm{O}_{2}$ concentration. The TG-DTG method is usually adopted to determine the ignition temperature and burn-out temperature of coal sample (Figure 8). The maximum peak point of the DTG curve is taken as a vertical line to intersect with the TG curve at Point A. The tangent line of the TG curve is taken at Point A. Point B at the beginning of weight loss on the TG curve is taken as a parallel line. The temperature corresponding to the intersection Point $C$ of the parallel line and the tangent line is the ignition temperature. Furthermore, a parallel line is drawn at the end of weight loss point on the TG curve, and the temperature corresponding to the intersection Point D between the parallel line and the tangent line is the burn-out temperature.

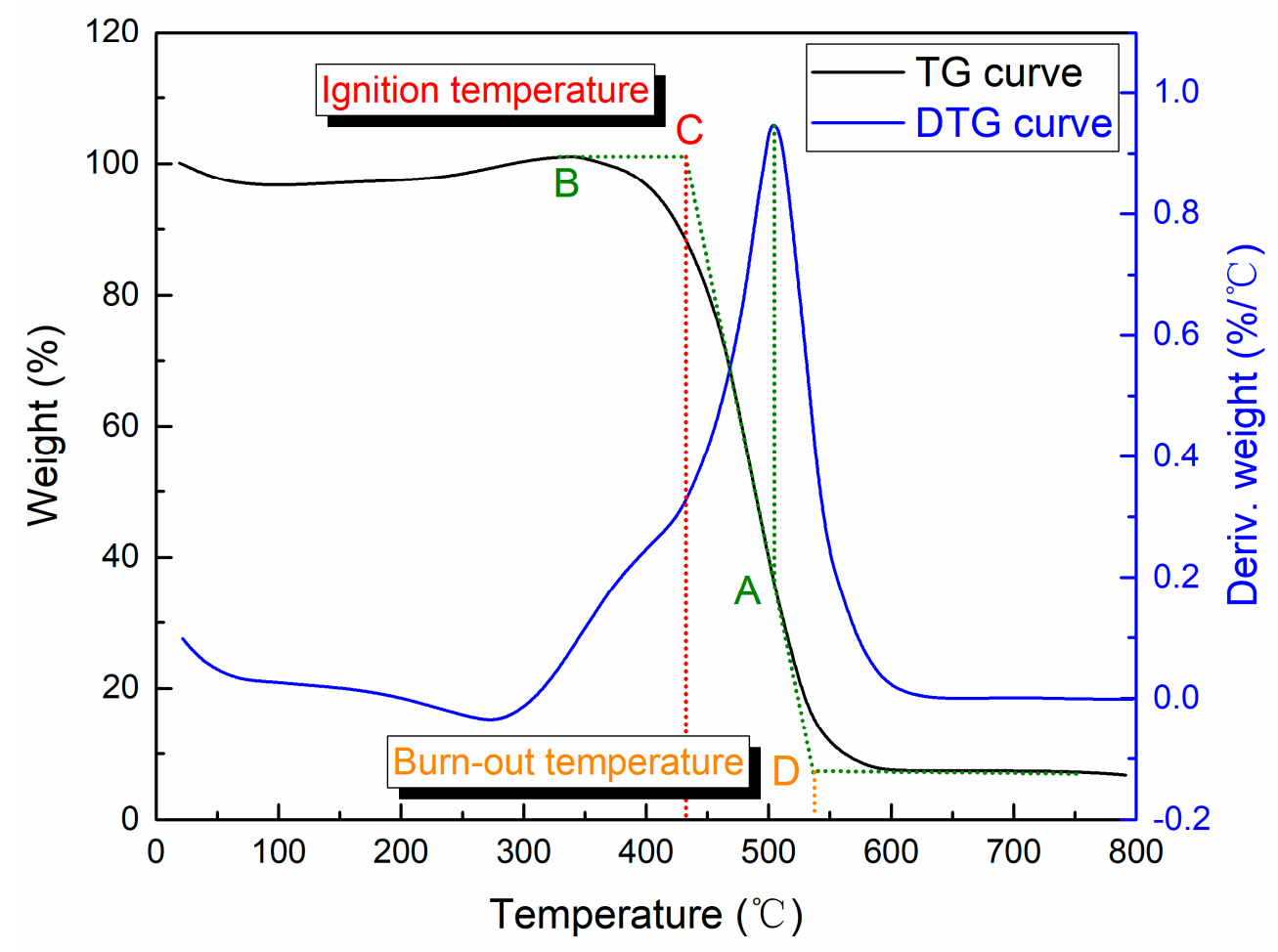

Figure 8. Definitions of ignition temperature and burn-out temperature.

The ignition temperature and burn-out temperature of coal samples in the $\mathrm{N}_{2}$ and $\mathrm{CO}_{2}$ atmospheres at different $\mathrm{O}_{2}$ concentrations are exhibited in Figures 9 and 10. 


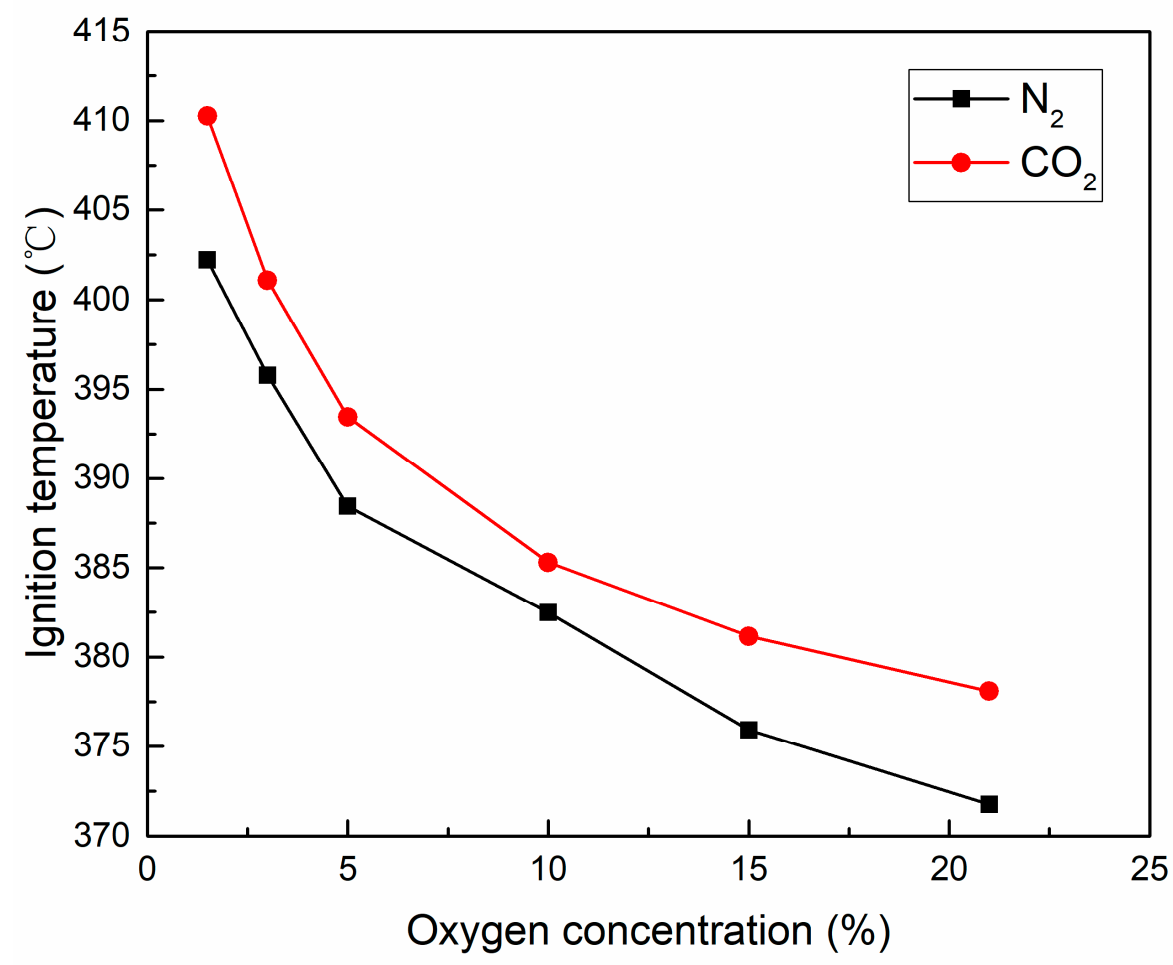

Figure 9. Ignition temperature of coal sample in the $\mathrm{N}_{2}$ and $\mathrm{CO}_{2}$ atmospheres.

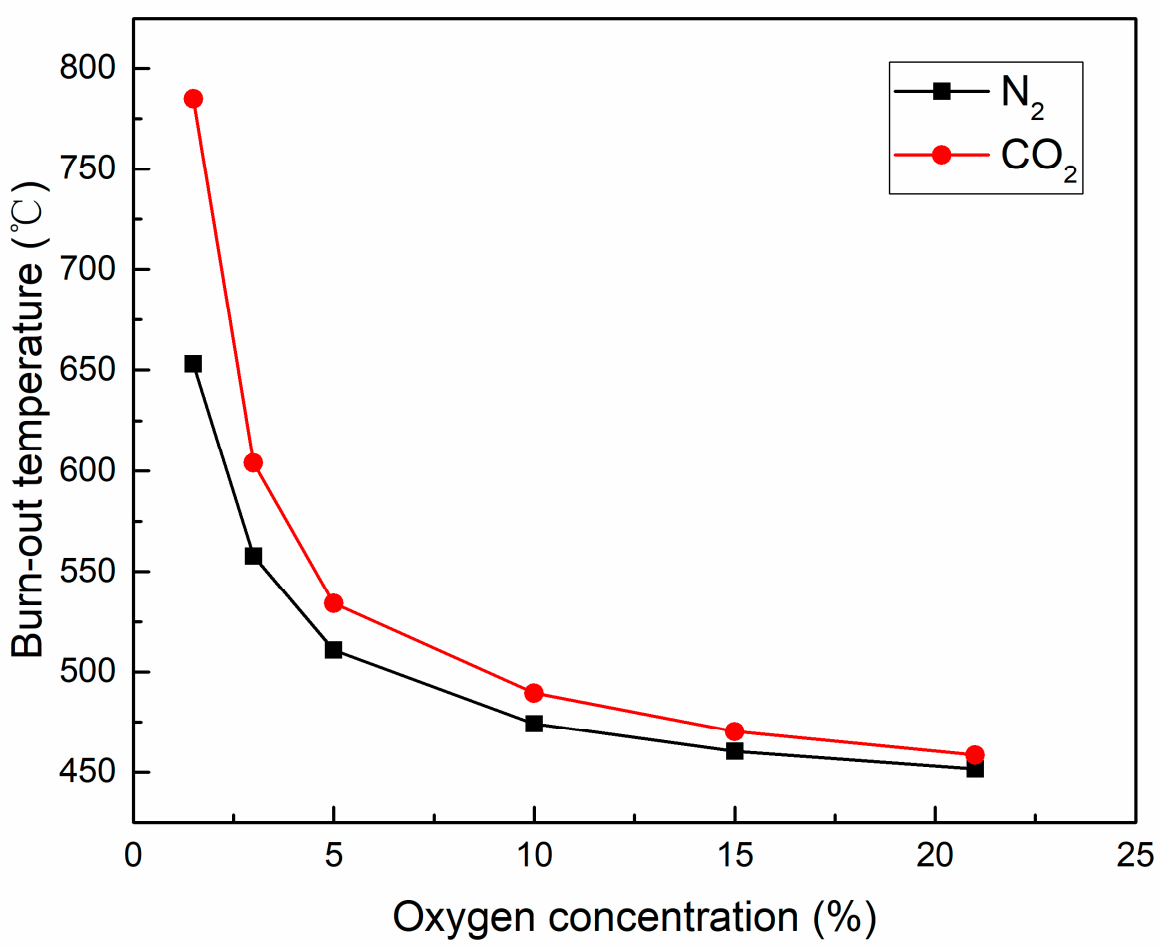

Figure 10. Burn-out temperature of coal sample in the $\mathrm{N}_{2}$ and $\mathrm{CO}_{2}$ atmospheres.

Under the inert gas conditions, with the decrease of $\mathrm{O}_{2}$ concentration, the ignition temperatures and the burn-out temperatures of coal samples increase. This indicates that increasing the inert gas concentrations can delay the process of coal oxidation and combustion reaction to a certain extent. The overall reaction rates of coal samples in the high-temperature combustion stage are determined by the gas diffusion rate and the oxidation reaction rate. In the process of coal oxidation and combustion, 
the $\mathrm{O}_{2}$ demand of active structure is fixed. At a low $\mathrm{O}_{2}$ concentration, the rates of gas diffusion and oxidation reaction are slow, and the time required for oxidation and combustion reaction is prolonged. With the increase of $\mathrm{O}_{2}$ concentration, the rates of gas diffusion and oxidation reaction are accelerated, and the time required for oxidation and combustion reaction is shortened.

\section{Conclusions}

In this paper, the inhibition effects of inert gases $\left(\mathrm{N}_{2}\right.$ and $\left.\mathrm{CO}_{2}\right)$ on low-temperature oxidation and high-temperature combustion of coal samples were investigated. The main conclusions are as follows:

In the low-temperature oxidation stage, with the decrease of $\mathrm{O}_{2}$ concentration, i.e., the increase of inert gas concentration, the heat release of coal sample gradually drops at an accelerated rate. The $\mathrm{O}_{2}$ concentration in the fire area should be minimized in order to improve the inhibition effect of inert gas on low-temperature oxidation of coal. The apparent activation energy of coal samples gradually increases with the decrease of $\mathrm{O}_{2}$ concentration. In the $\mathrm{N}_{2}$ and $\mathrm{CO}_{2}$ atmospheres, as the $\mathrm{O}_{2}$ concentration is reduced to $1.5 \%$ and $3 \%$, respectively, the value of apparent activation energy changes from negative to positive, and the spontaneous reaction transits to nonspontaneous reaction.

In the high-temperature combustion stage, the critical temperature of coal sample exhibits a W-shaped trend with the decrease of $\mathrm{O}_{2}$ concentration, but its overall trend is to increase with the decrease of $\mathrm{O}_{2}$ concentration. In the inert gas atmospheres, the maximum peak temperature, ignition temperature, and burn-out temperature of coal sample gradually increase with the decrease of $\mathrm{O}_{2}$ concentration. This signifies that the increase of inert gas concentration can delay the high-temperature combustion reaction of coal, and the lower the $\mathrm{O}_{2}$ concentration is, the better the inhibition effect on coal combustion will be. Moreover, when the $\mathrm{O}_{2}$ concentration is the same, the inhibition effect of $\mathrm{CO}_{2}$ on coal oxidation and spontaneous combustion is superior to that of $\mathrm{N}_{2}$.

Author Contributions: Conceptualization, Y.Z., J.X. and D.W.; Methodology, Y.Z. and J.X.; Experiment, J.X.; Writing —original draft preparation, Y.Z.; Writing—review and editing, Y.Z. All authors have read and agreed to the published version of the manuscript.

Funding: This work was supported by the National Natural Science Foundation of China (51974299).

Conflicts of Interest: The authors declare no conflict of interest.

\section{References}

1. Wolde-Rufael, Y. Coal consumption and economic growth revisited. Appl. Energy 2010, 87, $160-167$. [CrossRef]

2. Li, H.; Shi, S.; Lin, B.; Lu, J.; Ye, Q.; Lu, Y.; Wang, Z.; Hong, Y.; Zhu, X. Effects of microwave-assisted pyrolysis on the microstructure of bituminous coals. Energy 2019, 187, 115986. [CrossRef]

3. Xu, C.; Wang, H.; Wang, D.; Zhu, X.; Zhu, Y.; Bai, X.; Yang, Q. Improvement of Foaming Ability of Surfactant Solutions by Water-soluble Polymers: Experiment and Molecular Dynamics Simulation. Polymers 2020, 12, 571. [CrossRef]

4. Zhang, Y.; Zhang, Y.; Li, Y.; Li, Q.; Zhang, J.; Yang, C. Study on the characteristics of coal spontaneous combustion during the development and decaying processes. Process Saf. Environ. Prot. 2020, 138, 9-17. [CrossRef]

5. Zhu, Y.; Wang, D.; Shao, Z.; Xu, C.; Zhu, X.; Qi, X.; Liu, F. A statistical analysis of coalmine fires and explosions in China. Process Saf. Environ. Prot. 2019, 121, 357-366. [CrossRef]

6. Deng, J.; Qu, J.; Wang, Q.; Xiao, Y.; Cheng, Y.; Shu, C. Experimental data revealing explosion characteristics of methane, air, and coal mixtures. RSC Adv. 2019, 9, 24627. [CrossRef]

7. Zhou, G.; Ding, J.; Ma, Y.; Li, S.; Zhang, M. Synthesis and performance characterization of a novel wetting cementing agent for dust control during conveyor transport in coal mines. Powder Technol. 2020, 360, 165-176. [CrossRef]

8. Zhang, H.; Nie, W.; Yan, J.; Bao, Q.; Wang, H.; Jin, H.; Peng, H.; Chen, D.; Liu, Z.; Liu, Z.; et al. Preparation and performance study of a novel polymeric spraying dust suppression agent with enhanced wetting and coagulation properties for coal mine. Powder Technol. 2020, 364, 901-914. [CrossRef] 
9. Zhou, W.; Wang, H.; Wang, D.; Du, Y.; Zhang, K.; Zhang, J. The influence of pore structure of coal on characteristics of dust generation during the process of conical pick cutting. Powder Technol. 2020, 363, 559-568. [CrossRef]

10. Zhang, Y.; Hu, S.; Xia, T.; Liu, Y.; Pan, Z.; Zhou, F. A novel failure control technology of cross-measure borehole for gas drainage: A case study. Process Saf. Environ. Prot. 2020, 135, 144-156. [CrossRef]

11. Liu, Z.; Wang, W.; Yang, H.; Yu, S.; Xin, L. Experimental study on the fractal pattern of a coal body pore structure around a water injection bore. J. Energy Resour. Technol. 2020, 142, 012302. [CrossRef]

12. Zhong, X.; Kan, L.; Xin, H.; Qin, B.; Dou, G. Thermal effects and active group differentiation of low-rank coal during low-temperature oxidation under vacuum drying after water immersion. Fuel 2019, 236, 1204-1212. [CrossRef]

13. Tang, Y.; Si, S.; Zhong, X. Experimental investigation of the performance of an effective self-suctioning water mist generator for controlling underground coal fires. Process Saf. Environ. Prot. 2019, 126, 98-105. [CrossRef]

14. Ma, L.; Wang, D.; Kang, W.; Xin, H.; Dou, G. Comparison of the staged inhibitory effects of two ionic liquids on spontaneous combustion of coal based on in situ FTIR and micro-calorimetric kinetic analyses. Process Saf. Environ. Prot. 2019, 121, 326-337. [CrossRef]

15. Zhuo, H.; Qin, B.; Qin, Q.; Su, Z. Modeling and simulation of coal spontaneous combustion in a gob of shallow buried coal seams. Process Saf. Environ. Prot. 2019, 131, 246-254. [CrossRef]

16. Lu, W.; Guo, B.; Qi, G.; Cheng, W.; Yang, W. Experimental study on the effect of preinhibition temperature on the spontaneous combustion of coal based on an $\mathrm{MgCl}_{2}$ solution. Fuel 2020, 265, 117032. [CrossRef]

17. Shi, Q.; Qin, B. Experimental research on gel-stabilized foam designed to prevent and control spontaneous combustion of coal. Fuel 2019, 254, 115558. [CrossRef]

18. Tian, Z.; Lu, Y.; Liu, S.; Shi, S.; Li, H.; Ye, Q. Application of inorganic solidified foam to control the coexistence of unusual methane emission and spontaneous combustion of coal in the Luwa coal mine, China. Combust. Sci. Technol. 2020, 192, 638-656. [CrossRef]

19. Ren, X.; Hu, X.; Cheng, W.; Bian, S.; Zhao, Y.; Wu, M.; Xue, D.; Li, Y.; Lu, W.; Wang, P. Study of resource utilization and fire prevention characteristics of a novel gel formulated from coal mine sludge (MS). Fuel 2020, 267, 117261. [CrossRef]

20. Qi, X.; Chen, L.; Zhang, L.; Bai, C.; Xin, H.; Rao, Z. In situ FTIR study on real-time changes of active groups during lignite reaction under low oxygen concentration conditions. J. Energy Inst. 2019, 92, 1557-1566. [CrossRef]

21. Ray, S.K.; Singh, R.P. Recent developments and practices to control fire in underground coal mines. Fire Technol. 2007, 43, 285-300. [CrossRef]

22. Li, T.; Qi, Y.; Li, X.; Wang, J. Coal fire prevention in large areas over long term with a composite inert gas-A case study in Tangkou coal mine, China. Energ. Source Part A 2019. [CrossRef]

23. Shi, B.; Zhou, G.; Ma, L. Normalizing fire prevention technology and a ground fixed station for underground mine fires using liquid nitrogen: A case study. Fire Technol. 2018, 54, 1887-1893. [CrossRef]

24. Taraba, B.; Pavelek, Z. Study of coal oxidation behavior in re-opened sealed heating. J. Loss Prevent. Proc. 2016, 40, 433-436. [CrossRef]

25. Su, H.; Zhou, F.; Song, X.; Qiang, Z. Risk analysis of spontaneous coal combustion in steeply inclined longwall gobs using a sacled-down experimental set-up. Process Saf. Environ. Prot. 2017, 111, 1-12. [CrossRef]

26. Lei, B.; He, B.; Xiao, B.; Du, P.; Wu, B. Comparative study of single inert gas in confined space inhibiting open flame coal combustion. Fuel 2020, 265, 116976. [CrossRef]

27. Shao, H.; Jiang, S.; Wu, Z.; Zhang, W.; Wang, K. Comparative research on the influence of dioxide carbon nitrogen on performance of coal spontaneous combustion. J. China Coal Soc. 2014, 39, 2244-2249.

28. Liu, H.; Wang, F. Thermal characteristics and kinetic analysis of coal-oxygen reaction under the condition of inert gas. Int. J. Coal Prep. Util. 2019. [CrossRef]

29. Deng, J.; Ren, L.; Ma, L.; Qin, X.; Wang, W.; Liu, C. Low-temperature oxidation and reactivity of coal in $\mathrm{O}_{2} / \mathrm{N}_{2}$ and $\mathrm{O}_{2} / \mathrm{CO}_{2}$ atmospheres, a case of carboniferous-permian coal in Shaanxi, China. Environ. Earth Sci. 2019, 78, 234. [CrossRef]

30. Li, H.; Chen, X.; Shu, C.; Wang, Q.; Ma, T.; Bin, L. Effects of oxygen concentration on the macroscopic characteristic indexes of high-temperature oxidation of coal. J. Energy Inst. 2019, 92, 554-566. [CrossRef]

31. Ma, L.; Wang, Y.; Wu, R.; Ren, L.; Zou, L. Effect of low oxygen concentrations on the thermokinetics of coal combustion. Combust. Sci. Technol. 2020. [CrossRef] 
32. Ren, L.; Li, Q.; Deng, J.; Xiao, Y.; Ma, L.; Wang, W. Inhibiting effect of $\mathrm{CO}_{2}$ on the oxidative combustion thermodynamics of coal. RSC Adv. 2019, 9, 41126. [CrossRef]

33. Zhang, Y.; Li, Y.; Huang, Y.; Li, S.; Wang, W. Characteristics of mass, heat and gaseous products during coal spontaneous combustion using TG/DSC-FTIR technology. J. Therm. Anal. Calorim. 2018, 131, 2963-2974. [CrossRef]

34. Benfell, K.E.; Beamish, B.B.; Rodgers, K.A. Thermogravimetric analytical procedures for characterizing New Zealand and Eastern Australian coals. Thermochim. Acta 1996, 286, 67-74. [CrossRef] 